\title{
THE LANGUAGE OF DISPLACEMENT: AN ETHNOGRAPHIC STUDY OF COMMUNICATIVE PRACTICES IN URBAN MIGRANT COMMUNITIES
}

\author{
Lavanya Sinha \\ Delhi Public School, R. K. Puram \\ DOI: 10.46609/IJSSER.2020.v05i10.029 URL: https://doi.org/10.46609/IJSSER.2020.v05i10.029
}

\begin{abstract}
With the increase of urban migration in India and the consequent increase in clashes between migrants and the local population, it is crucial to examine measures to de-escalate conflict and promote the equality and inclusion of urban migrant populations. Inclusion of such populations is highly dependent on the preservation of their languages, communicative practices, cultures and dialects. However, migrant languages and dialects are increasingly erased due to forced assimilation, a lack of education, and a lack of documentation of the same. This has consequences ranging from the social and political exclusion of migrants, as well as cultural bereavement. This paper will examine the importance of the preservation of culture of migrants, and the consequences of the lack of knowledge about local dialects and practices. The paper will then propose policy measures and intervention to improve migrant literacy, and safeguard their cultural rights without compromising on their local languages and customs.
\end{abstract}

Keywords: Language, Ethnographic, Urban, migrant ,Culture

\section{Introduction}

The urban migrant crisis caused due to the COVID-19 lockdown in India, has brought to the fore the importance of recognizing the needs of urban migrants and a better understanding of their communities. With the increasing number of migrants moving to cities in India due to rapid urbanization and foreign and domestic investment, it is important to study the evolving use of language in the narration of their cultural identity, due to the increasing number of emerging method that migrant communities are using to convey their stories and grievances to wider audiences. This is further important to ensure that they are incorporated within urban communities with dignity, and that their constitutional and socio-economic rights are adequately safeguarded and treated with equality. 


\section{International Journal of Social Science and Economic Research}

ISSN: $2455-8834$

Volume:05, Issue:10 "October 2020"

Understanding the cultural identity of urban migrants through language is important, as migrants do not constitute a homogenous category, and migrants are differentiated according to gender, class, ethnicity, language and religion (UNESCO, 2013). The languages and communicative practices of migrants are further often forgotten in the debate on linguistic integration across the country, the discourse around which is most often limited to elite urban populations, politicians, intellectuals and academics (Narayan, 2017). However, the dialects of migrants are not taken into account. This is a conversation that cannot be ignored, given the increase in percentages of urban migrants as a proportion of the population. According to the census figures of 2011, Tamil Nadu's migrant population surged by $98 \%$ between 2001 and 2011 , Kerala's by 49\%, Karnataka's 50\% and Andhra Pradesh's 40\% (Narayan, 2017). Such a scenario will lead to an important reckoning with respect to whether migrants would have to make an effort to learn the languages of the states and integrate within the state's local culture (Narayan, 2017). The faultlines created by the disparities and the steady erosion or ignorance of migrants' cultural identity caused by linguistic and cultural differences are already visible in the form of the vandalism that has been aimed at the use of Hindi in public places in parts of Karnataka and Tamil Nadu (Narayan, 2017).

In addition, a lack of understanding and importance given to the languages and culture of migrants also serves to exclude them from the processes involved in daily citizenship and participation in the political process. Among the challenges: restricted access to basic needs such as identity documentation, social entitlements, housing, and financial services (Abbas and Varma, 2014). Many migrants - especially those who relocate to a place where the local language and culture is different from that of their region of origin-also face harassment and political exclusion (Abbas and Varma, 2014). Such an exclusion has been apparent in the arduous struggle faced by migrants who were forced to bear excruciating conditions in travelling to their homes post the imposition of COVID-19 lockdowns.

This paper will emphasise the need to undertake a study of the language, culture and communicative practices for migrants, and examine the particular practices adopted my migrant communities to preserve their cultural identities. The paper aims to shed light on the challenges that migrants face in terms of cultural and political exclusion, and suggest policy measures and interventions that can be adopted to support the inclusion of migrants as well as improve opportunities for literacy and academic advancement.

\section{Background}

In urban areas of India, there is a history of identity politics leading to clashes between local populations and migrant communities, with calls for their exclusion or forced integration. This has served to erode the linguistic identities of these communities, and erode the use of language 


\section{International Journal of Social Science and Economic Research}

ISSN: $2455-8834$

Volume:05, Issue:10 "October 2020"

as a tool for meaning making in the urban migrant community. For example, in Mumbai, one of Indi's largest urban hubs of industrial activity, nativist political parties since the 1960s have claimed that migrants threaten Marathi culture and usurp job opportunities, residential space, and amenities that rightfully belong to the local Maharashtrian population (Abbas and Varma, 2014). Although Mumbai is an example of an extreme case of marginalization of urban migrant communities, such a reality is unfortunately present in all Indian states, given that the states system, which is organized by language and cultural groups: since most Indian states are, by design, the local homelands of India's different ethnic and linguistic groups, migration between states often creates competitive politics between migrants and locals (Abbas and Varma, 2014).

For Indian migrant communities, the family unit is often the foundation of language and behavior, and consequently meaning making and narration of their cultural identities. In surveys conducted among migrant populations, on the whole, family related migration for females has been increasing during the last two decades (Bhagat, 2014). It would seem that male and female migration to urban areas are related as males move for employment and for better employment prospects whereas females follow them as a consequence of marriage or move later as soon as the male migrants settle down (Bhagat, 2014).

Rural-urban migrants are frequently bilingual in the regional standard language as well as in their village dialect. In Bombay, for example, many migrants speak Hindi or Marathi in addition to their native tongue. Religious celebrations, popular festivals, and political meetings are typically carried on in the regional language, which may be unintelligible to many attendees (U.S Library, n.d). Therefore, communal histories of urban migrants are often encoded in their language and particular rituals. There is also great variation in dialects and variations in speech which is dependent on the community as well social strata. However, linguistic functional dichotomy of English/major regional languages and major regional languages/tribal minority languages, which cause the loss of linguistic vitality and endanger the minority languages of India (Ivanova, 2013). In this context, the Indian educational system is based on the general assumption about the socioeconomic power of Indian languages, thus excluding most indigenous and tribal minority languages (ITM) from the school curricula towards marginalization (Ivanova, 2013). The invisibility of ITM leads to school failure and consequent poverty, thus causing a subtractive effect on the minority languages and the removal of ITM children from social and linguistic reality (Ivanova, 2013).

\section{Discussion}

The lack of documentation of India's diverse linguistic and cultural identities leads to the perception that urban migrants are illiterate or lack an identity that warrants inclusion, while they may well be literate in their local languages and dialects. Such an issue is compounded and 


\section{International Journal of Social Science and Economic Research}

ISSN: $2455-8834$

Volume:05, Issue:10 "October 2020"

exacerbated by the fact that migrants have limited access to education remain unaware of their legal rights and are unable to access an impartial forum to register their grievances. Women migrants are even more vulnerable to exploitation, possessing negligible or often lower educational qualifications than their male counterparts (UNESCO, 2013). As a result, they face harassment and other aspects of labour market discrimination. Due to their mobile status, migrants face difficulties in unionising, and remain a fragmented workforce (UNESCO, 2013). The further fragmentation of communities means that the languages disappear owing to the lack of cohesion and preservation of oral and written traditions, as well as a lack of opportunities for community based rituals and engagement. It is crucial that the language barrier be adequately addressed, to prevent further social, cultural and political marginalization. An example of an approach to prevent the displacement and erasure of language through lack of education is the work of Aide et Action, a civil society organization. Aide et Action has mobilised education volunteers from the source villages of the migrant children to teach them in their mother tongue (Aide et Action, n.d). These education volunteers are appointed on a seasonal basis and are paid jointly by Aide et Action and the Sarva Shiksha Abhiyan (SSA) of the destination state (Aide et Action, n.d). Additionally, text books are provided by SSA of the state for migrant children studying in different states (Aide et Action, n.d). After the children return to their source villages, education volunteers receive transfer certificates for the children from the respective SSAs at the destination (Aide et Action, n.d). Based on the number of students that have studied in worksite schools at the destination, Aide et Action writes a letter to the state SSA to reintegrate these children into the nearest schools to their home villages (Aide et Action, n.d). The education volunteers assist the parents in reintegrating children into the village school. This ensures that at an early level, the cultural expression and practices of migrant communities are preserved, while simultaneously addressing the educational divide that is a result of fragmentation and exclusion.

Such an approach is all the more important given that the impact of linguistic and cultural exclusion is often most prominently and strongly felt by the children of urban migrants in India. Seasonal migrants often take their children along when they migrate for work, which negatively impacts upon the regular and continued schooling of children (UNESCO, 2013). There is an overlap between the academic session in schools (June-April) and the seasonal migration cycle (November-June), on account of which migrant children who are enrolled in schools end up attending school only between June and November (UNESCO, 2013). This temporary discontinuation of study frequently results in their dropping out of school altogether. In the case that migrant children take up education at the destination, they face learning difficulties based on differences in academic curricula and language, especially in the case of inter-state migration (UNESCO, 2013). Such a situation is only compounded by the already existing lack of documentation of the communicative practices, dialects and local cultures of 


\section{International Journal of Social Science and Economic Research}

ISSN: $2455-8834$

Volume:05, Issue:10 "October 2020"

migrant communities and cements the erasure of their identities in a more permanent and everlasting manner.

Another crucial aspect to consider is the psychological effect of cultural bereavement, faced by migrants. Migration involves the loss of the familiar, including language (especially colloquial and dialect), attitudes, values, social structures and support networks, which leads to mental illnesses among migrants (Bhugra and Becker, 2005). Language, both written and spoken, is a cultural marker. Linguistic competence and economic stability are determinant factors prompting individuals to eventually leave their non-dominant cultural group, which typically is geographically bound, and venture into the dominant culture (Bhugra and Becker, 2005). The acculturation process that then occurs can cause serious and lasting consequences for the psyche of migrants, infringing on their right to live with basic dignity, physical and mental well-being. (Bhugra and Becker, 2005).

\section{Conclusion}

Potential policy interventions must focus on supporting urban migrant populations towards higher literacy rates and academic and literary opportunities. Moreover, such policies must emphasise inclusion, multiculturalism and a protection of migrant communities through frameworks of anti-discrimination. Creating employment in these languages is an important structural measure. Planning at the Central level must move towards the incorporation a microelement of language for planning for different districts and cultural regions (Narayan, 2017).

Civil society participation has provided promising results. For example, the Ajeevika Bureau is an NGO which provides services to migrants include registration and photo ID cards; skills training and placement services for jobs at urban destinations; legal aid and literacy programs; organization of worker collectives at destination; assistance accessing banking and social security; and strengthening support systems for women and families affected by male migration (Abbas and Varma, 2014; Sharma, 2017). SETU is the Centre For Social Knowledge and Action's intervention to provide elementary education to children in the 11-14 years age group in seasonal hostels (UNESCO, 2013). These hostels enabled children to stay back in their villages and continue their education uninterrupted when their parents migrated for work. These hostels in the home villages were functional during the months the workers migrated (UNESCO, 2013). Such an approach is also encouraging as it develops skills, while allowing for the preservation of local cultures and communicative practices, without compromising on the language.

In conclusion, policy makers and civil society organizations must fundamentally rethink the inclusion of migrant populations from viewpoint of inclusion rather than one of assimilation. 
International Journal of Social Science and Economic Research

ISSN: 2455-8834

Volume:05, Issue:10 "October 2020"

Only then will true progress be made in the preservation and documentation of their cultural and linguistic practices, preserving the plurality of democratic society. Overall, societal attitudes must change regarding the inclusion of migrants and the government has a key role to play in ensuring their rights to be treated equally with respect to their culture and languages are protected.

\section{References}

Abbas, R, and Varma, D, (2014), 'Internal Labor Migration in India Raises Integration Challenges for Migrants', Migration Policy Institute, https://www.migrationpolicy.org/article/internal-labor-migration-india-raises-integrationchallenges-migrants

Aide et Action, (n.d), 'Projects', https://aea-southasia.org/

Bhagat, R, (2014), 'Urban Migration Trends, Challenges And Opportunities In India', International Organization for Migration, https://www.iom.int/sites/default/files/our_work/ICP/MPR/WMR-2015-Background-PaperRBhagat.pdf

Bhugra, D, and Becker, M, (2005), 'Migration, cultural bereavement and cultural identity, World Psychiatry, Vol.4, Issue 1, p 18-24

Ivanova, R, (2013), 'Multilingualism and Language Diversity in Urban Areas. Acquisition, identities, space, education', in, Peter Siemund, Ingrid Gogolin, Monika Edith Schulz and Julia Davydova (eds.) 2013, http://lym.linguas.net/Download.axd?type=ArticleItem\&id=119

Narayan, H, (2017), 'India, land of many tongues', The Hindu, https://www.thehindu.com/thread/arts-culture-society/india-a-land-of-manytongues/article19445187.ece

Sharma, K, (2017), 'India has 139 million internal migrants. They must not be forgotten', World Economic Forum, https://www.weforum.org/agenda/2017/10/india-has-139-million-internalmigrants-we-must-not-forget-them/

U.S Library of Congress, (n.d), 'The Social Context of Language', http://countrystudies.us/india/69.htm\#: :text=Rural\%2Durban\%20migrants\%20are\%20frequent1 y,addition\%20to\%20their\%20native\%20tongue. 
International Journal of Social Science and Economic Research

ISSN: 2455-8834

Volume:05, Issue:10 "October 2020"

UNESCO, (2013), 'Social Inclusion of Internal Migrants in IndiaInternal Migration in India Initiative', UNICEF, https://unesdoc.unesco.org/ark:/48223/pf0000223702 